\title{
Hydrogen Production by a Steam-Reformer for Heavy Hydrocarbons*
}

\author{
Katsuya HIRATA**, Masashi NAKAMORI**, Kazuya TANIGAWA**, \\ Fukutaro KATAOKA**, Yasutaka FUJIMOTO**, Toshio SHINOKI***, \\ Hirochika TANIGAWA $* * * *$ and Jiro FUNAKI** \\ ** Department of Mechanical Engineering, Doshisha University, Kyoto 610-0321, Japan \\ *** Mitsubishi Electric Corporation, 8-1-1, Tsukaguchi-Honmachi, Amagasaki 661-8661, Japan \\ **** Maizuru National College of Technology, Maizuru 625-8511, Japan \\ E-mail: khirata@mail.doshisha.ac.jp
}

\begin{abstract}
The authors develop a small and simple steam-reforming reactor in a home-use size for $n$-dodecane as a heavy-hydrocarbons fuel. Under such a well-controlled condition by a thermal diffuser as the reactor satisfies two target-temperature criteria, the authors measure the inside-temperature profile and the hydrogen molar fraction (concentration) $C_{\mathrm{H} 2}$, together with the molar fractions $C_{\mathrm{CH} 4}, C_{\mathrm{CO}}$ and $C_{\mathrm{CO} 2}$ of other main gass components such as $\mathrm{CH}_{4}, \mathrm{CO}$ and $\mathrm{CO}_{2}$, respectively, using a gas chromatograph. In addition, the authors conduct theoretical calculations based on the thermal-equilibrium theory, and reveal $C_{\mathrm{H} 2}, C_{\mathrm{CH} 4}, C_{\mathrm{CO}}$ and $C_{\mathrm{CO} 2}$, as well as experiments. As a result, the authors successfully achieve suitable inside-temperature profiles. The steam-reforming reaction becomes more active at the position where temperature $T>800 \mathrm{~K}$. The effects of the steam-to-carbon molar ratio $S / C$ upon $C_{\mathrm{H} 2}, C_{\mathrm{CH} 4}, C_{\mathrm{CO}}$ and $C_{\mathrm{CO} 2}$ are shown, experimentally and theoretically. The experimental results agree well with the theoretical ones. Besides, carbon balance and conversion ratio show high accuracy in experiments.
\end{abstract}

Key words: Steam Reforming, $n$-dodecane, Heavy Hydrocarbon, Hydrogen

\section{Introduction}

Recently, environmental problems due to the excessive waists of the fossil fuel have become serious. So, we are attempting the preventions of air pollutions by $\mathrm{NO}_{x}, \mathrm{SO}_{x}$, etc., and the reduction of carbon-dioxide $\left(\mathrm{CO}_{2}\right)$ emissions which lead up to the global warming. In such a context, the fuel cell is one alternative to future electric power plants. In general, hydrogen $\left(\mathrm{H}_{2}\right)$ for the fuel-cell power plants is manufactured from hydrocarbons $\left(\mathrm{C}_{n} \mathrm{H}_{m}\right)$ originated in the fossil fuel, using the steam-reforming methods with catalysts. ${ }^{(1),(2)}$

From a theoretical point of view, the steam-reforming method is the way to manufacture the most moles of $\mathrm{H}_{2}$, in comparison with other methods such as the partial-oxidation-reforming method and the mixture of both, namely, the auto-thermal reforming method. The steam-reforming method is applied not only for liquids, but also for gases. In fact, the steam reformings of methanol and methane are the most common for hydrogen production in industrial fields.

As the fuel-cell fuels which have prevailing infrastructures in service, we can suppose town gas, liquefied petroleum gas (LPG), gasoline, diesel oil and kerosene in Japan. Among them, town gas or natural gas, whose main constituent is methane, has been studied more actively. And, it has been used in many steam-reforming plants with well-established technologies.

On the other hand, hydrocarbons fuels, such as gasoline, diesel oil, kerosene, dimethyl 
ether, ethanol and methanol, are liquid in the normal temperature. So, they have some advantages: namely, (1) consumers can safely transport, store and handle them; (2) many related prevailing infrastructures for some of them have already been in service. However, they have other difficulties that they contain some sulfur, and that the reactor tends to be coking. As the contained sulfur can poison catalysts, we need the desulfurisation as a pre-treatment process. The coking causes both the reduction of effective catalyst's surface, and the flow blockage due to the attachment to the surface. Therefore, we need the temperature control in catalyst-layer beds. Specifically speaking, we should avoid such coking conditions as the incomplete vaporisation of incoming fuel and the extremely-high temperature at the upstream of the catalyst-layer bed.

The temperature control is important from another point of view, in addition to the prevention of the coking. That is, the optimum catalyst performance can be achieved by maintaining the reaction temperature in a suitable range, especially inside the catalyst-layer bed. So, in the actual operations of the steam-reforming methods, fine temperature control in the reactor is a key technology for stable and efficient hydrogen production. In particular, the temperatures at the upstream and downstream of the catalyst-layer bed are very important. Specifically speaking, in the upstream of the catalyst, the temperature control is necessary both to avoid the production of the coking and to avoid imperfect evaporation of the fuel. In the downstream of the catalyst, the temperature control becomes important to maintain the optimum catalyst performance.

Thus far, there have been some researches concerning the reforming of heavy-hydrocarbons liquid fuels. Suzuki et al. (2000) ${ }^{(3)}$ reported the long-term production of $\mathrm{H}_{2}$ from kerosene using $\mathrm{Ru} / \mathrm{CeO}_{2}-\mathrm{Al}_{2} \mathrm{O}_{3}$ catalyst. Fukunaga et al. (2003) ${ }^{(4)}$ developed a kerosene processing system for polymer electrolyte fuel cells (PEFCs), and simulated the system's performance for evaluation. Kobori et al. (2003) ${ }^{(5)}$ numerically analysed kerosene steam-reformings. Saito \& Kisen $(2003)^{(6)}$ developed desulfurization chemical and catalysts for kerosene reformers. Liu et al. $(2004)^{(7)}$ investigated the autothermal reforming of $n$-dodecane and $n$-hexadecane as surrogates for diesel fuels. Koseki (2004) ${ }^{(8)}$ experimentally investigated the characteristics of a diffusion flame combustor for a small-scale fuel-cell system. Muramoto et al. (2009) ${ }^{(9)}$ have experimentally estimated the durability of $\mathrm{Ru} / \mathrm{CeO}_{2} / \mathrm{Al}_{2} \mathrm{O}_{3}$ catalyst for the reforming of $n$-dodecane. And, Yoon et al. (2009) ${ }^{(10)}$ have experimentally studied a one- $\mathrm{kW}_{\mathrm{e}}$-class autothermal reforming of kerosene for solid oxide fuel cells (SOFCs).

However, such past researches are chemical approaches or theoretical estimations for ideal systems. And there have been few reports based on the thermo and fluid mechanics, for practical designs of the reactors. So, in the present research, we examine $n$-dodecane $\left(\mathrm{C}_{12} \mathrm{H}_{26}\right)$ as a heavy-hydrocarbons fuel without sulfur, which is a main constituent of kerosene. And, we develop a small and simple steam-reformer for $n$-dodecane in a home-use size. (A part of the present research has been reported as a note. ${ }^{(11)}$ ) According to the above-mentioned temperature requirements, we require both the thermal conditions that the temperature $T=600 \mathrm{~K}$ at the upstream end of the catalyst-layer bed and that $T=1000 \mathrm{~K}$ at the downstream end (see Matsumoto $(2003)^{(12)}$ ). As is mentioned above, the former is related with the coking, and the latter is linked to the catalyst's performance. We measure the temperature profiles in a catalyst-layer bed inside the reactor using sheathed thermocouples of the type $\mathrm{K}$, to confirm the effectivity of the control by a thermal-control device, a thermal diffuser. And, we measure the molar fractions $C_{\mathrm{H} 2}, C_{\mathrm{CH} 4}, C_{\mathrm{CO}}$ and $C_{\mathrm{CO} 2}$ of main gas components such as $\mathrm{H}_{2}, \mathrm{CH}_{4}, \mathrm{CO}$ and $\mathrm{CO}_{2}$ using a gas chromatograph, respectively. In addition, we conduct numerical calculations based on the thermal-equilibrium theory, and reveal $C_{\mathrm{H} 2}, C_{\mathrm{CH} 4}, C_{\mathrm{CO}}$ and $C_{\mathrm{CO} 2}$, as well as experiments. Then, we reveal the effects of the steam-to-carbon molar ratio $S / C$ upon $C_{\mathrm{H} 2}, C_{\mathrm{CH} 4}, C_{\mathrm{CO}}$ and $C_{\mathrm{CO} 2}$ experimentally and theoretically. Besides, we show the effects of $S / C$ upon both 
carbon balance and conversion ratio.

\section{Experimental Method}

\subsection{Experimental apparatus}

Figure 1 shows the schematic diagram of the present experimental apparatus. Pumps (1) and (2) feed the present system with water and $n$-dodecane, respectively. Through a mixer (3) which is a T-shaped junction, the fuel consisted of both water and $n$-dodecane is perfectly vaporised at a vaporisation unit (4). We fill a reactor between co-axial cylinders (5) and (6) with $\mathrm{Ru} / \mathrm{Al}_{2} \mathrm{O}_{3}$ catalyst (7) of about $720 \mathrm{cc}(=790 \mathrm{~g}$ ), with $\mathrm{Ru} 0.4 \mathrm{wt} \%$. The substrate of the catalyst is a sphere with a diameter of $3 \mathrm{~mm}$. The reactor has an annular cross section of $60.5 \mathrm{~mm}$ in inner diameter, $93.6 \mathrm{~mm}$ in outer diameter and $1,002 \mathrm{~mm}^{2}$ in cross-section area. The fuel is preheated at about $1000 \mathrm{~K}^{(13)}$, which is enough high for the reforming reaction, using electric heaters (8), and the catalyst is heated using a gas burner (9) of $1.1 \mathrm{~kW}$ heat capacity. Temperature is controlled by a thermal diffuser (10) and the gasu burner. Temperature is measured by sheathed thermocouples (11) of type $\mathrm{K}$ with diameters of $1.6 \mathrm{~mm}$. Sheathed thermo couples of type K are horizontally inserted inward from an outer-pipe wall of the reactor. The gas from the reactor passes a cold trap (12) with a cooling system (13), where condensed or aqueous constituent parts are absorbed. Next, the gas passes a dryer (14), and is analysed using a gas chromatograph and a flowmeter (15). Finally, the gas is led to an exhaust duct.

\subsection{Temperature measurement inside a reactor}

We measure temperature $T$ at six positions from I to $\mathrm{VI}$ in a steam-reforming reactor. In Fig. 2 and Table 1, the measurement positions are shown in details, with the present coordinate system. Precisely speaking, the measurement positions divide a domain from $z=$ $80 \mathrm{~mm}$ to $230 \mathrm{~mm}$ into five sections, equally. We should note that the downstream end of a catalyst-layer bed is at $z=65 \mathrm{~mm}$, and that the upstream end is at $z=245 \mathrm{~mm}$. At each of the position, a sheathed thermocouple of type $\mathrm{K}$ is horizontally inserted inward from an outer-pipe wall of the reactor. Strictly speaking, it is not sure that all the temperatures $T_{\mathrm{I}}-T_{\mathrm{VI}}$ represent catalyst's temperatures. That is, we should take such complicated influences into consideration as the relation between gas and catalyst temperatures, the catalyst-temperature ununiformity based on local endothermic reactions, the heat conduction inside the catalyst-layer bed, the heat radiation from gas/catalyst and the thermo couple characteristics, which depend upon many factors such as gas flow rate and so on.

Prior to the main experiments, we have confirmed the controllability of temperature profile by the thermal diffuser. The thermal diffuser can adjust the burning-gas velocity which is linked to the heat transfer to the inner pipe. Then, the enhanced heat transfer could cause the sensible-heat release, which could increase the thermal gradient on the catalyst-layer bed. That is, we have conducted a series of preliminary experiments, in order to achieve the expected thermal conditions by choosing appropriate value of a thermal-diffuser position $h$ and a burner position $H$. To specify such optimum values of $h$ and $H$, in these preliminary experiments, we measure temperatures at only two positions I ( $z$ $=230 \mathrm{~mm})$ and VI $(z=80 \mathrm{~mm})$, which are near the upstream end and the downstream end of the catalyst-layer bed, respectively. Specifically speaking, we measure the temperature $T_{\mathrm{I}}$ at the position I and the temperature $T_{\mathrm{VI}}$ at the position VI in a steady condition, at $h=40$, 60 and $\infty \mathrm{mm}$ and at $H=-20,0$ and $15 \mathrm{~mm}$. As $T_{\mathrm{VI}}$ is considered to be the most important temperature, we usually regard $T_{\mathrm{VI}}$ as a representative temperature of the reactor. The steady condition is defined as the condition where temperature fluctuation in one hour is less than $\pm 5 \mathrm{~K}$. At $h=40 \mathrm{~mm}$, the corn base of the thermal diffuser is in the same level as the downstream end of the catalyst-layer bed. At $h=60 \mathrm{~mm}$, the corn apex of the thermal 
diffuser is in the same level as the downstream end. And, at $h=\infty \mathrm{mm}$, the thermal diffuser is not inserted. As a result, we can confirm the controllability by $h$ and $H$. That is, we can easily control the thermal profile without the control of flesh-air supply into the burner, but in a limited controllable range. As is mentioned in Section 1, we try to achieve both the thermal conditions. Concretely speaking, we suppose such two conditions as $T=600 \mathrm{~K}$ at the upstream end and as $T=970 \mathrm{~K}$ at the downstream end. Then, we could almost achieve these target conditions at $h=60 \mathrm{~mm}$ and $H=0 \mathrm{~mm}$.

In the main experiments, where $h$ and $H$ are fixed to $60 \mathrm{~mm}$ and $0 \mathrm{~mm}$ respectively, we first preheat the reactor, adjusting the burner for each $S / C$. After the enough long preheat which achieves $T_{\mathrm{VI}} \approx 900 \mathrm{~K}$, we start to supply $\mathrm{H}_{2} \mathrm{O}$ with a flow rate $Q_{\mathrm{w}}$ into the reactor. The tested range of water flow rate $Q_{\mathrm{w}}$ is $11.4-22.9 \mathrm{cc} / \mathrm{min}$, and $n$-dodecane flow rate $Q_{\mathrm{d}}$ is $2.6-3.5 \mathrm{cc} / \mathrm{min}$ in the preliminary experiments or $4.0 \mathrm{cc} / \mathrm{min}$ in the main experiments. Table 2 shows $Q_{\mathrm{w}}$ for each $S / C$, in the main experiments. Eventually, $T_{\mathrm{VI}}$ becomes stable to a constant temperature of $970 \pm 10 \mathrm{~K}$. Empirically, we need about 1 hour to stabilise the reactor temperature after the $\mathrm{H}_{2} \mathrm{O}$ supply. Then, we start to supply $\mathrm{C}_{12} \mathrm{H}_{26}$ with a flow rate $Q_{\mathrm{d}}=4.0 \mathrm{cc} / \mathrm{min}$, in addition to $\mathrm{H}_{2} \mathrm{O}$. We define $t$ as the time from a start of the $\mathrm{C}_{12} \mathrm{H}_{26}$ supply. By the $\mathrm{C}_{12} \mathrm{H}_{26}$ supply, we often observe the increase of $T_{\mathrm{I}}$ and the decreases of $T_{\mathrm{II}}-T_{\mathrm{VI}}$. Thus, we re-adjust the heat supplies by the electric heaters and the gas burner corresponding to the values of $S / C$ and the liquid-hourly space velocity $L H S V$ (see Shinoki et al. ${ }^{(2)}$ for its definition), in order to achieve the two thermal conditions such as $T_{\mathrm{I}}=600 \mathrm{~K}$ and $T_{\mathrm{VI}}=970$ $\mathrm{K}$. We usually complete this re-adjustment at $t<900 \mathrm{~s}$.

Through all the experiments, we hold two criteria on thermal control, in addition to the two thermal conditions. One is referred to as a criterion $\alpha$. According to the criterion $\alpha$, we stop operations in order to avoid the coking (the carbon formation), when $T_{\mathrm{I}}$ reaches $670 \mathrm{~K}$. Against the coking, we monitor the pressure loss of the reactor, carbon balance and conversion ratio, in addition to the criterion $\alpha$. The other is referred to as a criterion $\beta$. According to the criterion $\beta$, we stop operations in order to avoid both the apparatus' breakdown and the catalyst sintering, when anyone of $T_{\mathrm{I}}-T_{\mathrm{VI}}$ exceeds in $1100 \mathrm{~K}$. - Of course, we frequently conduct the visual examination of catalyst condition through all the measurements. -

\subsection{Molar fraction measurement}

We use a gas chromatograph (SHIMAZU GC-3BT), to measure the molar fraction of reformed-gas main components. It's column is a linked two packed columns (SHINCARBON ST, $2 \mathrm{~m} \times 3 \mathrm{~mm} \phi$, stainless steel), whose temperature is fixed to $358 \mathrm{~K}$. The tested gas volume of the present gas chromatograph is $0.5 \mathrm{ml}$. As its carrier gas, we use argon.

Because the present gas chromatograph is applicable only for dry gas, we conduct a cold-trap process of the outlet gas from the reactor in order to remove normal-temperature liquid constituents except for water. Next, we conduct the removal of steam, using a silica-gel dryer. Finally, we measure the molar fraction of the dry-gas components, using the above analyser.

\subsection{Reforming reactions and steam-to-carbon ratio}

We manufacture hydrogen $\mathrm{H}_{2}$ from $n$-dodecane $\mathrm{C}_{12} \mathrm{H}_{26}$ and steam $\mathrm{H}_{2} \mathrm{O}$, using catalyst with a temperature $T$ of about $1000 \mathrm{~K}$. This steam-reforming is described by the following equation (e.g., see Matsumoto $\left.(2003)^{(12)}\right)$. 


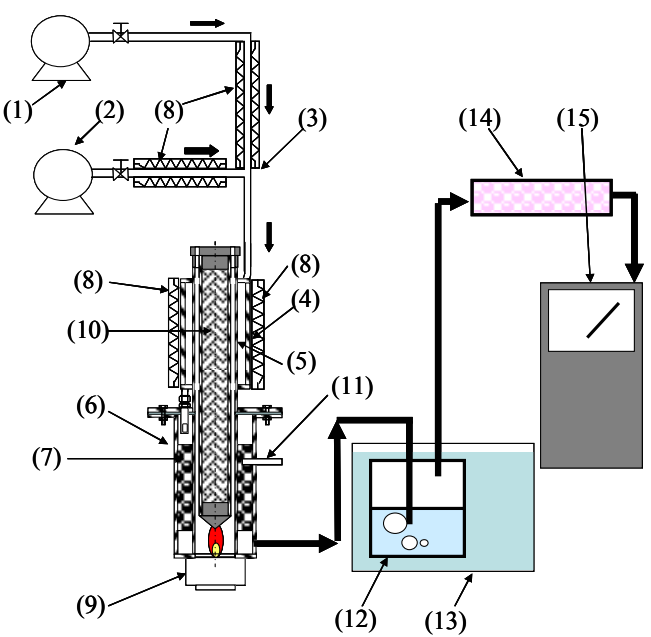

Fig. 1. Experimental apparatus. (1) Pump for water, (2) pump for fuel, (3) mixer, (4) vaporisation unit, (5) inner pipe, (6) outer pipe, (7) catalyst, (8) electric heater, (9) gas burner, (10) thermal diffuser, (11) sheathed thermocouple, (12) cold trap, (13) cooling system, (14) dryer, (15) gas chromatograph and flowmeter.

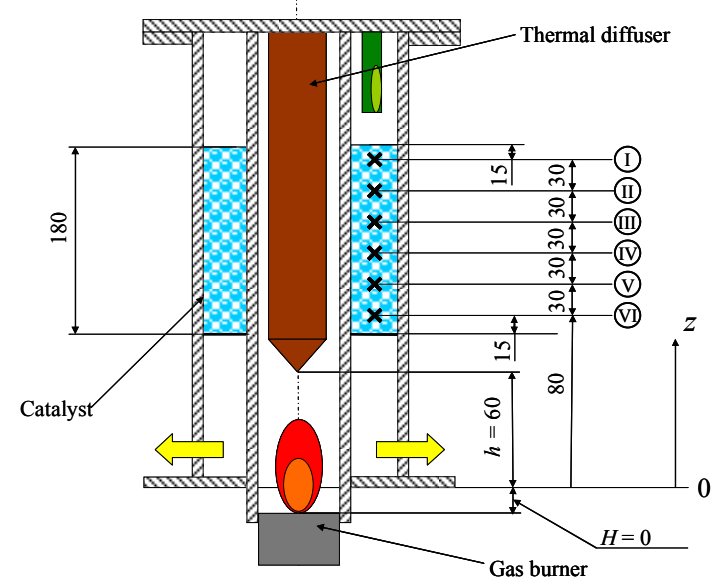

Fig. 2. Close-up view of a reactor, together with a coordinate system and temperature-measurement positions (unit: $\mathrm{mm}$ ).

Table 1. Temperature-measurement positions.

\begin{tabular}{|c|c|c|}
\hline Point & Position $z[\mathrm{~mm}]$ & Temperature \\
\hline I & 230.0 & $T_{\mathrm{I}}$ \\
\hline II & 200.0 & $T_{\mathrm{II}}$ \\
\hline III & 170.0 & $T_{\mathrm{III}}$ \\
\hline IV & 140.0 & $T_{\mathrm{IV}}$ \\
\hline V & 110.0 & $T_{\mathrm{V}}$ \\
\hline VI & 80.0 & $T_{\mathrm{VI}}$ \\
\hline
\end{tabular}

Table 2. Experimental Conditions $\left(Q_{\mathrm{d}}=4.0 \mathrm{cc} / \mathrm{min}\right)$.

\begin{tabular}{|c|c|c|c|c|c|}
\hline$S / C$ & 3.0 & 3.5 & 4.0 & 5.0 & 6.0 \\
\hline$Q_{\mathrm{w}[\mathrm{cc} / \mathrm{min}]}$ & 11.4 & 13.3 & 15.2 & 19.0 & 22.9 \\
\hline
\end{tabular}




$$
\mathrm{C}_{12} \mathrm{H}_{26}+24 \mathrm{H}_{2} \mathrm{O} \rightarrow 37 \mathrm{H}_{2}+12 \mathrm{CO}_{2}-1372 \mathrm{~kJ} / \mathrm{mol}
$$

Eq. (1) is an endothermic reaction, which is supposed to be at $T=298 \mathrm{~K}$ with gas-phase $\mathrm{C}_{12} \mathrm{H}_{26}$ and $\mathrm{H}_{2} \mathrm{O}$.

The actual phenomenon is complicated, accompanying the other many reactions and the other various products. However, main products are only four such as $\mathrm{H}_{2}, \mathrm{CH}_{4}$, $\mathrm{CO}$ and $\mathrm{CO}_{2}$, and the others are negligible. The following two equations are the main reactions except for Eq. (1).

$$
\begin{aligned}
& \mathrm{CO}+\mathrm{H}_{2} \mathrm{O} \underset{\leftarrow}{\leftarrow} \mathrm{CO}_{2}+\mathrm{H}_{2}+41 \mathrm{~kJ} / \mathrm{mol} . \\
& \mathrm{CO}+3 \mathrm{H}_{2} \underset{\mathrm{CH}_{4}}{\longrightarrow}+\mathrm{H}_{2} \mathrm{O}+206 \mathrm{~kJ} / \mathrm{mol} .
\end{aligned}
$$

Here, Eq. (2) is referred to as the water-gas-shift reaction, and Eq. (3) is the methanation reaction. Both equations are exothermic reactions. However, from a total point of view, the contribution of Eq. (1) on thermal balance is much large. So, even if we consider the other reactions such as Eqs. (2) and (3), the total reaction is endothermic.

The steam-to-carbon ratio $S / C$ is defined as the ratio of the mole of steam $\mathrm{H}_{2} \mathrm{O}$ to that of carbon $\mathrm{C}$ involved in the fuel hydrocarbons. From a theoretical point of view based on Eq. (1), if $S / C=2$, all $\mathrm{C}_{12} \mathrm{H}_{26}$ can be transformed into $\mathrm{H}_{2}$ and $\mathrm{CO}_{2}$. Then, for $S / C<2$, it becomes more frequent to coke.

\subsection{Numerical procedure}

We can predict the composition of the outlet gas from the reactor by chemical equilibria (e.g., see Uematsu $(2004)^{(13)}$ ). As is mentioned above, the actual phenomenon is complicated, consisting of many reactions related with the other various products. Now, we suppose that the reaction of Eq. (1) completely proceeds. And, we calculate chemical equilibria using the other main reactions of Eqs. (2) and (3) to get the molar fraction of $\mathrm{H}_{2}$, $\mathrm{CH}_{4}, \mathrm{CO}$ and $\mathrm{CO}_{2}$.

Each equilibrium constant $K_{\mathrm{r}}$ is given by the following equation, where $\Delta G[\mathrm{~kJ} / \mathrm{mol}], T$ $[\mathrm{K}], R[\mathrm{~kJ} /(\mathrm{K} \mathrm{mol})]$ denote the Gibbs energy (e.g., see Uematsu $\left.(2004)^{(14)}\right)$, reaction temperature and the gas constant, respectively.

$$
K_{\mathrm{r}}=\exp \left(\frac{-\Delta G}{R T}\right)=\exp \left(\frac{-\Delta G}{8.31 T}\right) .
$$

We suppose $T=973 \mathrm{~K}$. The value of $\Delta G$ is as follows.

$$
\Delta G=\Delta H-T \Delta S,
$$

where $\Delta H$ and $\Delta S$ denote enthalpy and entropy, respectively.

The equilibrium constants $K_{\mathrm{r}}^{(2)}$ and $K_{\mathrm{r}}^{(3)}$ corresponding to Eqs. (2) and (3) are

$$
K_{\mathrm{r}}^{(2)}=\frac{P_{\mathrm{CO} 2} \times P_{\mathrm{H} 2}}{P_{\mathrm{CO}} \times P_{\mathrm{H} 2 \mathrm{O}}},
$$

and

$$
K_{\mathrm{r}}{ }^{(3)}=\frac{P_{\mathrm{CH} 4} \times P_{\mathrm{H} 2 \mathrm{O}}}{P_{\mathrm{CO}} \times P_{\mathrm{H} 2}^{3}},
$$

respectively. Here, $P_{\mathrm{H} 2}, P_{\mathrm{CH} 4}, P_{\mathrm{CO}}, P_{\mathrm{CO} 2}$ and $P_{\mathrm{H} 2 \mathrm{O}}$ represent the partial pressures of the corresponding gas components. 


\subsection{Carbon balance and conversion ratio}

$n$-dodecane conversion ratio $X_{\mathrm{C} 12 \mathrm{H} 26}$ is an index that shows the molar ratio of $n$-dodecane resolved in a reactor. In general, $X_{\mathrm{C} 12 \mathrm{H} 26}$ is calculated by the following equation, using both a molar flow rate (a mole amount per time) $\left[F_{\mathrm{C} 12 \mathrm{H} 26}\right]_{\text {out }}[\mathrm{mol} / \mathrm{min}]$ of the $n$-dodecane from the reactor and a molar flow rate $\left[F_{\mathrm{C} 12 \mathrm{H} 26}\right]_{\text {in }}$ of the $n$-dodecane into the reactor. $^{(15)}$

$$
X_{\mathrm{C} 12 \mathrm{H} 26}=\frac{\left[F_{\mathrm{C} 12 \mathrm{H} 26}\right]_{\text {in }}-\left[F_{\mathrm{C} 12 \mathrm{H} 26}\right]_{\text {out }}}{\left[F_{\mathrm{C} 12 \mathrm{H} 26}\right]_{\text {in }}} \times 100[\%] .
$$

In the present study, because the direct measurement of $\left[F_{\mathrm{C} 12 \mathrm{H} 26}\right]_{\text {out }}$ is technically difficult, we consider the both total molar flow rates of carbon from and into the reactor. Then, we determine $X_{\mathrm{C} 12 \mathrm{H} 26}$ by the following equation.

$$
X_{\mathrm{C} 12 \mathrm{H} 26}=\frac{\left[F_{\mathrm{CH} 4}\right]_{\text {out }}+\left[F_{\mathrm{CO}}\right]_{\text {out }}+\left[F_{\mathrm{CO} 2}\right]_{\text {out }}}{12 \times\left[F_{\mathrm{C} 12 \mathrm{H} 26}\right]_{\text {in }}} \times 100[\%] .
$$

where $\left[F_{\mathrm{CH} 4}\right]_{\text {out }},\left[F_{\mathrm{CO}}\right]_{\text {out }}$ and $\left[F_{\mathrm{CO} 2}\right]_{\text {out }}$ denote the molar flow rates of such main constituents as $\mathrm{CH}_{4}, \mathrm{CO}$ and $\mathrm{CO}_{2}$ from the reactor, respectively.

Carbon-balance error $C B E[\%]$ is an index that shows the presence of the other constituents involved in the outlet gas except for the main four constituents like $\mathrm{H}_{2}, \mathrm{CH}_{4}$, $\mathrm{CO}$ and $\mathrm{CO}_{2}$. $C B E$ is calculated by the following equation, using a difference between the actual mole amount of $\mathrm{C}$ involved in the main four constituents from the reactor and the mole amount of $\mathrm{C}$ involved in the reacted $n$-dodecane at the reactor.

with

$$
C B E=\frac{|A-B|}{A} \times 100[\%],
$$

$$
A=\left[M_{\mathrm{CO}}\right]_{\text {out }}+\left[M_{\mathrm{CO} 2}\right]_{\text {out }}+\left[M_{\mathrm{CH} 4}\right]_{\text {out }}
$$

and

$$
B=-\frac{12\left\{2\left[M_{\mathrm{H} 2}\right]_{\mathrm{out}}+4\left[M_{\mathrm{CH} 4}\right]_{\mathrm{out}}-2\left(\left[M_{\mathrm{CO}}\right]_{\mathrm{out}}+2\left[M_{\mathrm{CO} 2}\right]_{\mathrm{out}}\right)\right\}}{26} .
$$

We determine the latter of $\mathrm{C}$ by the measurements of molar ratios of $\mathrm{H}, \mathrm{C}$ and $\mathrm{O}$ involved in the outlet gas, supposing Eq. (1) by which we calculate the mole amounts of $\mathrm{C}$ and $\mathrm{H}$ of the reacted $n$-dodecane and the mole amounts of $\mathrm{H}$ and $\mathrm{O}$ of the reacted water. And, $\left[M_{x}\right]_{\text {out }}[\mathrm{mol}]$ denotes a mole amount of each constituent $x$. Equation (10) can be simplified as follows.

$$
C B E=\frac{\mid\left[25\left[M_{\mathrm{CO}}\right]_{\text {out }}+37\left[M_{\mathrm{CO} 2}\right]_{\text {out }}-11\left[M_{\mathrm{CH} 4}\right]_{\text {out }}-12\left[M_{\mathrm{H} 2}\right]_{\mathrm{out}}\right]}{13\left(\left[M_{\mathrm{CO}}\right]_{\text {out }}+\left[M_{\mathrm{CO} 2}\right]_{\text {out }}+\left[M_{\mathrm{CH} 4}\right]_{\text {out }}\right)} \times 100[\%] .
$$

\section{Results and Discussion}

\subsection{Temperature inside a reactor}

Figure 3 shows an example of the time development of the temperature profile inside a catalyst-layer bed. Specifically speaking, two profiles shown by open symbols are at $t=900$ $\mathrm{s}$ and $1800 \mathrm{~s}$, for $S / C=6, L H S V=0.25 \mathrm{~h}^{-1}, Q_{\mathrm{w}}=17.0 \mathrm{cc} / \mathrm{min}$ and $Q_{\mathrm{d}}=3.0 \mathrm{cc} / \mathrm{min}$, together with a profile at $t=0$ (see later).

We can confirm a good agreement between both the profiles at $t=900 \mathrm{~s}$ and $1800 \mathrm{~s}$. That is, even at $t=900 \mathrm{~s}$, the profile has already been in steady condition. Besides temperature monotonically tend to increase in the leeward direction (from I to VI ). And, such two thermal conditions as $T_{\mathrm{I}}=600 \mathrm{~K}$ and $T_{\mathrm{VI}}=970 \mathrm{~K}$ are almost achieved. Of course, we can confirm that both the criteria $\alpha$ and $\beta$ are satisfied. 


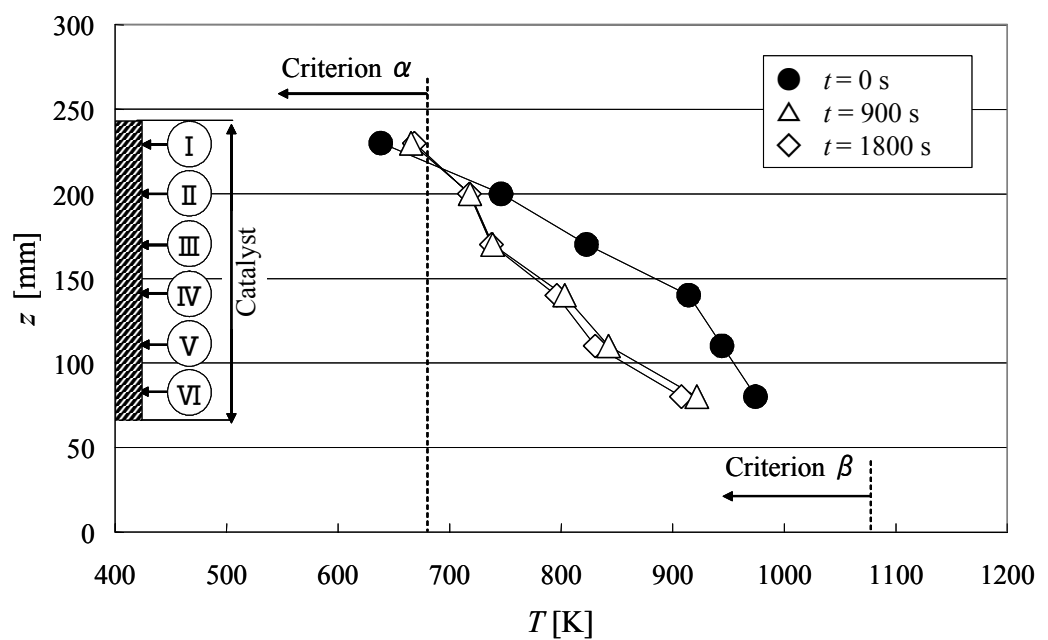

Fig. 3. Time development of the temperature profile inside a catalyst-layer bed $(S / C=6$, $\left.L H S V=0.25 \mathrm{~h}^{-1}, Q_{\mathrm{w}}=17.0 \mathrm{cc} / \mathrm{min}, Q_{\mathrm{d}}=3.0 \mathrm{cc} / \mathrm{min}\right)$.

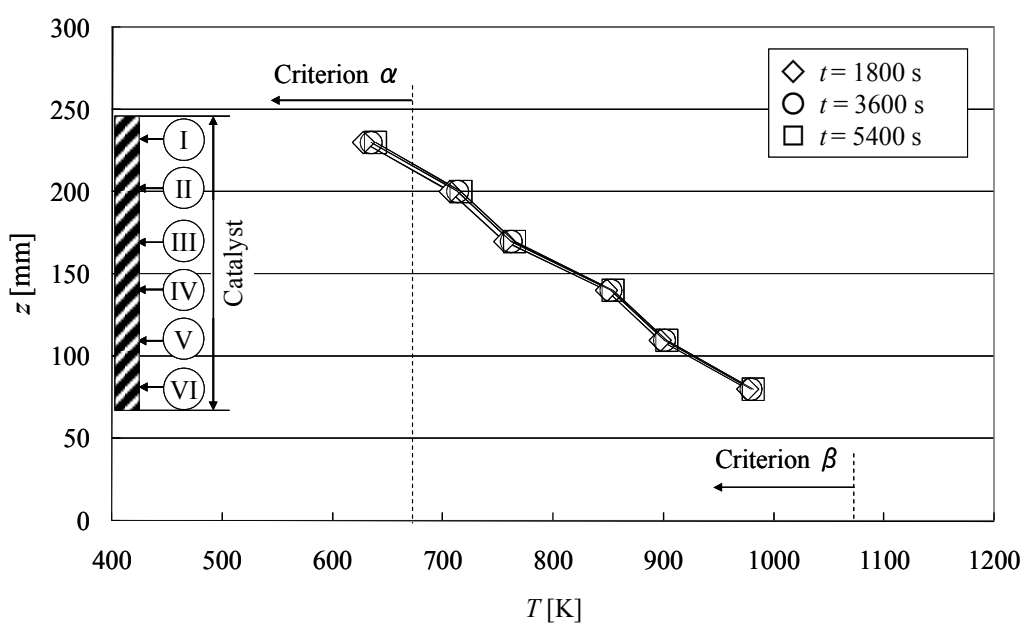

Fig. 4. Time development of the temperature profile inside a catalyst-layer bed $(S / C=4$, $\left.L H S V=0.33 \mathrm{~h}^{-1}, Q_{\mathrm{w}}=15.2 \mathrm{cc} / \mathrm{min}, Q_{\mathrm{d}}=4.0 \mathrm{cc} / \mathrm{min}\right)$.

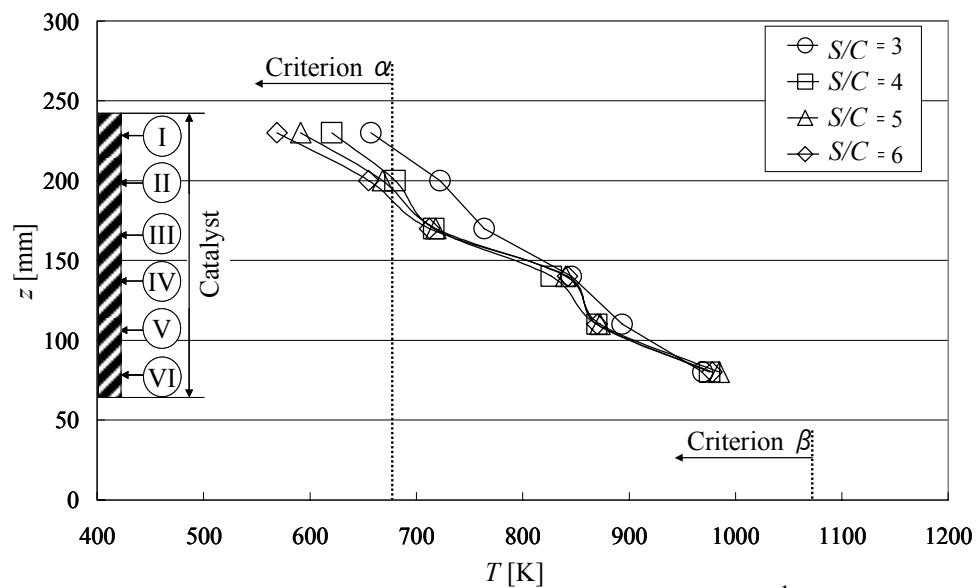

Fig. 5. Temperature profile inside a catalyst-layer bed $\left(L H S V=0.33 \mathrm{~h}^{-1}, Q_{\mathrm{d}}=4.0 \mathrm{cc} / \mathrm{min}, t=\right.$ $3600 \mathrm{~s})$. 
Figure 3 also shows the profile at $t=0$ just before the $\mathrm{C}_{12} \mathrm{H}_{26}$ supply, as an example of profiles at $t \leq 0$ for the comparison with those at $t>0$. Especially in Fig. 3, in order to observe the influence of endothermic reactions upon the profile, $Q_{\mathrm{w}}=20.0 \mathrm{cc} / \mathrm{min}$ at $t \leq 0$. That is, the sum of $Q_{\mathrm{d}}$ and $Q_{\mathrm{w}}$ at $t \leq 0$ is the same as that at $t>0$. In addition, the heat supply at $t>0$ by both electric heaters and a gas burner keeps to be constant with that at $t \leq 0$. We can find that $T_{\mathrm{IV}}$ and $T_{\mathrm{V}}$ at $t=0$ are much higher than those at $t=900 \mathrm{~s}$ and $1800 \mathrm{~s}$, respectively, though $T_{\mathrm{I}}$ at $t=0$ is slightly lower than those at $t=900 \mathrm{~s}$ and $1800 \mathrm{~s}$ owing to higher temperature of the inlet gas. We can consider that those temperature differences are related to an endothermic reaction at $t>0$, namely, the steam reforming reaction, not to the latent heat of $\mathrm{C}_{12} \mathrm{H}_{26}$. In fact, $T_{\mathrm{IV}}>800 \mathrm{~K}$. This well corresponds to the thermal-equilibrium theory as will be shown in Subsection 3.2 where a remarkable change in enthalpy is expected to occur at $T_{\mathrm{R}} \approx 800 \mathrm{~K}$. In summary, those temperature differences well correspond to enhanced endothermic reactions at $T_{\mathrm{R}} \geq 800 \mathrm{~K}$. - For precise discussion based on thermal-equilibrium theory, we have to consider reaction rates, which are affected by temperature, chemical reactions, catalyst types and so on. For example, if we assume the Arrhenius' equation for reaction rates, activation energies and frequency factors depend upon chemical reactions, catalyst types and so on.-

Figure 4 shows an example the temperature profiles inside the catalyst-layer bed, when they become stable enough time later (more than $900 \mathrm{~s}$ ) after the $\mathrm{C}_{12} \mathrm{H}_{26}$ supply. Namely, the figure represents the results for $S / C=4, L H S V=0.33 \mathrm{~h}^{-1}, Q_{\mathrm{w}}=15.2 \mathrm{cc} / \mathrm{min}$ and $Q_{\mathrm{d}}=4.0$ $\mathrm{cc} / \mathrm{min}$, at $t=1800,3600$ and $5400 \mathrm{~s}$. In contrast to Fig. 3, in Fig. 4 as well as Figs 5-9, experimental procedure is in an ordinary way, as described in Subsection 2.2. That is, $Q_{\mathrm{w}}$ at $t \leq 0$ is the same as that at $t>0$. And, we re-adjust the heat supplies by the electric heaters and the gas burner corresponding to the values of $S / C$ and $L H S V$, in order to achieve the two thermal conditions such as $T_{\mathrm{I}}=600 \mathrm{~K}$ and $T_{\mathrm{VI}}=970 \mathrm{~K}$.

First, we see the result at $t=1800 \mathrm{~s}$. We can see that temperature $T$ monotonically increases in the streamwise direction. The increase is approximately in a linear manner. Moreover, we can see that, we finally succeed in the achievement of the target conditions. Of course, even in Fig. 3, we can confirm that both the criteria $\alpha$ and $\beta$ are satisfied.

Second, we can confirm a good agreement among the profiles at $t=1800,3600$ and $5400 \mathrm{~s}$. This fact suggests that the temperature profiles are stable, being independent of $t$. Thus, hereafter, we consider the results only at $t=3600 \mathrm{~s}$.

Figure 5 shows the temperature profiles inside the catalyst-layer bed, for several values of $S / C$. Namely, the figure represents the results for $S / C=3-6, L H S V=0.33 \mathrm{~h}^{-1}, Q_{\mathrm{d}}=4.0$ $\mathrm{cc} / \mathrm{min}$, at $t=3600 \mathrm{~s}$. Again, we can confirm the three features for each $S / C$ : (1) the monotonic increase of $T$ in the streamwise direction in a linear manner, (2) the achievement of the target thermal conditions, and (3) the satisfaction of both the criteria $\alpha$ and $\beta$. In summary, by the present reactor, we have succeeded in the expected temperature profile being independent of $S / C$ not only from a qualitative viewpoint but also from a quantitative viewpoint.

\subsection{Molar fraction by theory}

Now, we consider the molar fraction $C_{x}$ under the target thermal conditions. Figure 6 shows the theoretical results predicted by the thermal-equilibrium theory based on the stream-reforming reactions Eqs. (1)-(3), in Subsections 2.4 and 2.5. Namely, in the figure, the predicted main-gas-component molar fraction $C_{\mathrm{H} 2}, C_{\mathrm{CH} 4}, C_{\mathrm{CO}}$ and $C_{\mathrm{CO} 2}$ are plotted against the steam-to-carbon molar ratio $S / C$, at reaction temperatures $T$ 's $=873,923973$ and $1023 \mathrm{~K}$. As well as Fig. 6, Fig. 7 shows $C_{x}$ predicted by the thermal-equilibrium theory plotted against $T$, for $S / C=3$ and 5 .

At first, we see the results at $T=973 \mathrm{~K}$ in Fig. $6, C_{\mathrm{H} 2}$ theoretically achieves about $70 \%$, being independent of $S / C$. The molar fractions $C_{\mathrm{CH} 4}, C_{\mathrm{CO}}$ and $C_{\mathrm{CO} 2}$ of the other main 
components are all small, that is, less than $1 / 3$ of $C_{\mathrm{H} 2}$, being independent of $S / C$. In particular, $C_{\mathrm{CH} 4}$ nearly equals zero. More specifically, both $C_{\mathrm{H} 2}$ and $C_{\mathrm{CO} 2}$ slightly increases, as $S / C$ increases. And, both $C_{\mathrm{CH} 4}$ and $C_{\mathrm{CO}}$ slightly decreases, as $S / C$ increases. If we compare the result at $T=973 \mathrm{~K}$ with those at $T \neq 973 \mathrm{~K}$, we can find that all the results are almost the same from a qualitative viewpoint, and that such $S / C$ effects are enhanced by the decrease of $T$. - Strictly speaking, the discrepancies between the molar fractions at $T=973$ $\mathrm{K}$ and those at $T=1023 \mathrm{~K}$ are negligibly small.-

Second, we see Fig. 7. For both values of $S / C, C_{\mathrm{H} 2}$ monotonically increases, as $T$ increases. More specifically, for $S / C=3, C_{\mathrm{H} 2}$ approaches to a constant value of about $70 \%$ at $T>973 \mathrm{~K}$, where $C_{\mathrm{H} 2}$ is independent of $T$. As well, for $S / C=5, C_{\mathrm{H} 2}$ approaches to a constant value of about $70 \%$ at $T>923 \mathrm{~K}$, where $C_{\mathrm{H} 2}$ is independent of $T$. From a practical point of view, a smaller $S / C$, which represents a smaller latent heat for redundant steam vaporisation, contributes to the improvement of the total thermal efficiency of a steam reformer. So, the result suggests that the present $n$-dodecane steam reforming should be carried out at $T \approx 973 \mathrm{~K}$ near the downstream end of a catalyst-layer bed.

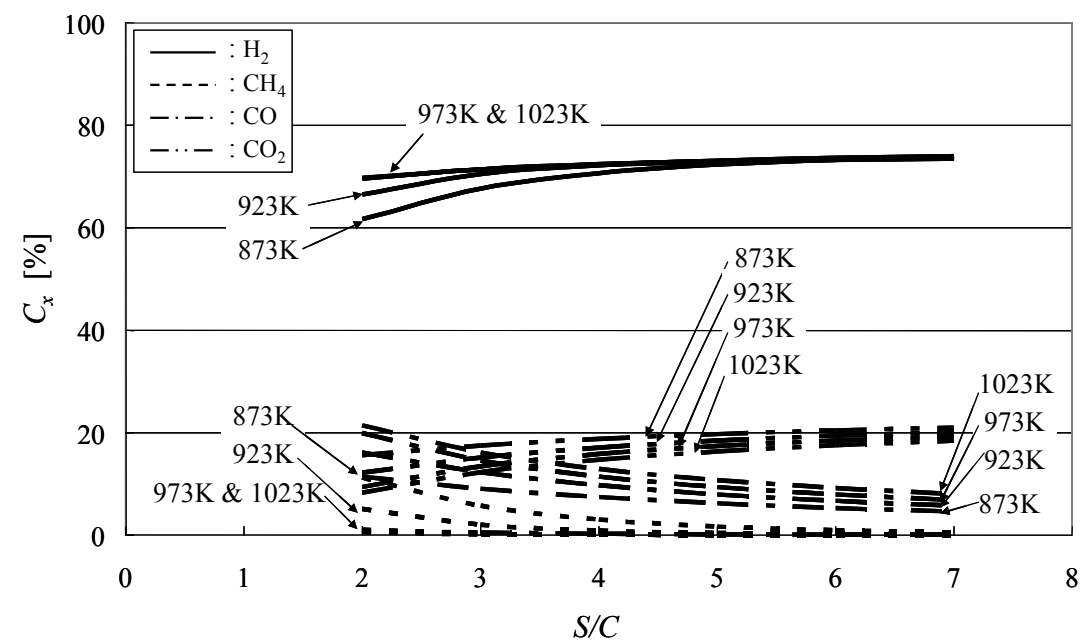

Fig. 6. Molar fraction $C_{x}$ predicted by the thermal-equilibrium theory versus steam-to-carbon molar ratios $S / C(T=873,923,973,1023 \mathrm{~K})$.

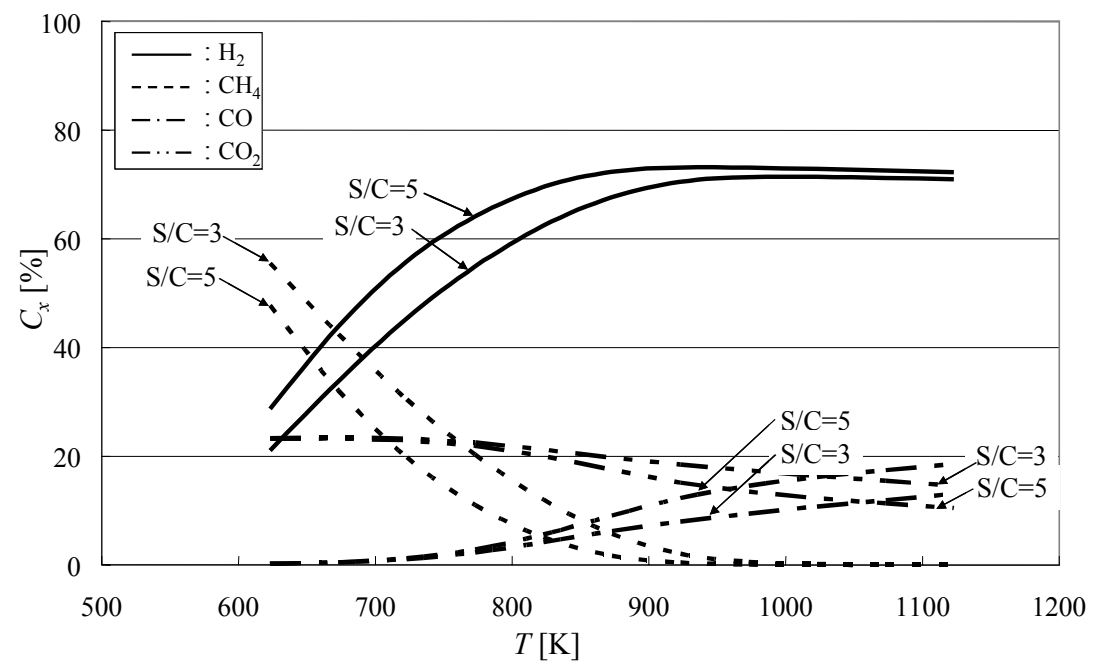

Fig. 7. Molar fraction $C_{x}$ predicted by the thermal-equilibrium theory versus reaction temperature $T(S / C=3,5)$. 


\subsection{Molar fraction by experiment}

Figure 8 shows the experimental results analysed by a gas chromatograph, together with the theoretical ones at $T=973 \mathrm{~K}$ which are denoted by lines. Namely, the figure shows the effect of the steam-to-carbon ratio $S / C$ upon $C_{\mathrm{H} 2}, C_{\mathrm{CH} 4}, C_{\mathrm{CO}}$ and $C_{\mathrm{CO} 2}$ for $L H S V=0.33$ $\mathrm{h}^{-1}$ at $t=3600 \mathrm{~s}$, where we fix the $n$-dodecane flow rate $Q_{\mathrm{d}}$ to a constant value of $4.0 \mathrm{cc} / \mathrm{min}$. As the water flow rate $Q_{\mathrm{w}}$ varies from $11.4 \mathrm{cc} / \mathrm{min}$ to $22.9 \mathrm{cc} / \mathrm{min}, S / C$ varies from 3 to 6 . $T_{\mathrm{VI}}$ is fixed to $970 \mathrm{~K}$, which is close to the theory. For comparison, solid symbols in the figure show the experiments for kerosene at $T=1100 \mathrm{~K}$ by Suzuki et al. $(2000)^{(3)}-$ We can confirm that their results are close to the present ones for $S / C=3$ and 5.-

Incidentally speaking, we have confirmed the coking at $S / C=2.0$, which is a lower limit for all $\mathrm{C}_{12} \mathrm{H}_{26}$ reaction in Eq. (1). Then, all the data for $S / C \leq 2.0$ are not plotted in the figure.

To conclude, the experimental results agree with the theoretical ones for $S / C \geq 3$, not only qualitatively but also quantitatively. More concretely, we can see that $C_{\mathrm{H} 2}$ is stable in time constant to about $70 \%$, being independent of $S / C$. All the other main-gas-component molar fraction are much smaller than $C_{\mathrm{H} 2}$. That is, $C_{\mathrm{CH} 4}$ and $C_{\mathrm{CO}}$ are always less than $5 \%$ and $10 \%$, respectively. $C_{\mathrm{CO} 2}$ is approximately equal to $20 \%$. Strictly speaking, we can again confirm such tendencies as $C_{\mathrm{CO} 2}$ slightly increases with increasing $S / C$ and as both $C_{\mathrm{CH} 4}$ and $C_{\mathrm{CO}}$ slightly decreases with increasing $S / C$, as well as in the theory.

Specifically speaking, the discrepancy between the experimental $C_{\mathrm{H} 2}$ and the theoretical $C_{\mathrm{H} 2}$ slightly tends to increase, as $S / C$ decreases. We can confirm similar tendencies on $C_{\mathrm{CH} 4}, C_{\mathrm{CO}}$ and $C_{\mathrm{CO} 2}$, as well as $C_{\mathrm{H} 2}$. The reasons for these tendencies are considered to be as follows: (1) intermediate products increase with decreasing $S / C$; (2) flow inside the reactor is modified depending on $S / C$; (3) reforming reactions become less uniform with decreasing $S / C$.

Concerning the first reason, we should point out that we cannot detect any other components except for the main-gas components through all the experiments for various $S / C$ 's. - See Subsection 3.4 for more discussion about the first reason.-

Concerning the second reason, we should primary estimate the value of the Reynolds number $R e$. Now, we can define three kinds of $R e$ : a Reynolds number $R e_{\mathrm{VU}}$ inside the vaporisation unit, a Reynolds number $R e_{\mathrm{VUjet}}$ of the jet from the vaporisation unit into the reactor, and a Reynolds number $R e_{\mathrm{CLB}}$ in the catalyst-layer bed. $R e_{\mathrm{CLB}}$ is based on the mean flow velocity inside the reactor with no catalyst layer as a characteristic velocity scale, and based on the mean diameter of catalytic substraits as a characteristic length scale, because we suppose the Darcian flow. In the present study, $R e_{\mathrm{VU}} \simeq R e_{\mathrm{VUjet}} \simeq 3000-8000$, and $R e_{\mathrm{CLB}}=5-20$. We should note that all the three Reynolds numbers increase with decreasing $T$ or with increasing $S / C$, under such a condition as $L H S V$ is kept to be constant. The present test ranges of $R e_{\mathrm{VU}}$ and $R e_{\mathrm{VUjet}}$ suggest that the flow could be turbulent inside and from the vaporisation unit. On the other hand, the flow in the catalyst-layer bed could be turbulent for higher $S / C$, and could be in the transitional state between laminar and turbulent flows for lower $S / C$. Thus, it is possible for the flow in the catalyst-layer bed to depend upon $S / C$. Besides, taking chemical reactions into consideration in addition to the above-discussed Reynolds number effect, we should regard the following two factors: less-uniformity in catalyst packing and swirling flow inside the reactor. For the former factor, we point out that all catalytic substrates are fine and almost spherical. And, the present filling factor is estimated to be about 0.45 , which is almost the same as the theoretical closest packing. Thus, we could ignore the local Reynolds number effect due to the less-uniformity in catalyst packing. For the latter factor, we point out that the swirling flow inside the reactor might make the influence of $R e_{\mathrm{Vujet}}$ more sensitive, breaking the axial symmetry of the swirling flow about the reactor's centre axis. Fortunately, we could ignore the swirling-flow 
factor, because thermo-couples measurements show that the azimuthal temperature distributions inside the reactor in various experimental conditions are almost flat.

Concerning the third reason, we should regard the less-uniformity of local $S / C$ in the catalyst-layer bed owing to incomplete mixing of $n$-dodecane and water, in addition to the less-uniformity of flow related with the second reason. This less-uniformity of local $S / C$ can cause the less-uniformity in steam-reforming reactions. The less-uniformity of local $S / C$ is likely to be sensitive to the value of "so-called" total $S / C$. The reasons for the incomplete mixing are considered to be as follows: the hydrophoby of $n$-dodecane and the much-higher boiling temperature of $n$-dodecane $(489 \mathrm{~K}$ ) than water. Regarding the latter, we should note that phases and velocities of $n$-dodecane and water at the intermediate temperature between water and $n$-dodecane boiling points are different inside the vaporisation unit and that the vaporisation of liquid-phane $n$-dodecane in steam could cause the condensation of steam due to latent heat. When we assume the incomplete mixing, local $S / C$ varies in the range centring "total" $S / C$. As we can consider that the range becomes relatively large with decreasing "total" $S / C$, then the influences of $S / C$ on molar fractions intensify with decreasing $S / C$. This is consistent with the present results. So, the less-uniformity of reforming reactions is regarded to be one of the most probable reasons.

\subsection{Carbon balance and conversion ratio}

Figure 9 shows carbon-balance error $C B E$ and conversion ratio $X_{\mathrm{C} 12 \mathrm{H} 26}$ plotted against $S / C$ for $L H S V=0.33 \mathrm{~h}^{-1} Q_{\mathrm{d}}=4.0 \mathrm{cc} / \mathrm{min}$ and $T_{\mathrm{VI}}=970 \mathrm{~K}$ at $t=3600 \mathrm{~s}$. In the figure, $C B E$ and $X_{\mathrm{C} 12 \mathrm{H} 26}$ are denoted by solid triangle and diamond, respectively.

At first, we consider $C B E$. $C B E$ is always less than $10 \%$, being independent of $S / C$. This suggests that there exist little amounts of components except for the main gases such as $\mathrm{H}_{2}, \mathrm{CH}_{4}, \mathrm{CO}$ and $\mathrm{CO}_{2}$. It should be noted that $C B E$ is less than $10 \%$ even at small $S / C$, if we discuss the intermediate products in Subsection 3.3. The increase of the intermediate products affects the total carbon balance, and leads to the increase of $C B E$. Then, we can ignore the increase of the intermediate products even at small $S / C$.

Second, we consider $X_{\mathrm{C} 12 \mathrm{H} 26} . X_{\mathrm{C} 12 \mathrm{H} 26}$ is always about $90 \%$, being independent of $S / C$. Strictly speaking, especially for $S / C<4, X_{\mathrm{C} 12 \mathrm{H} 26}$ is slightly smaller than $90 \%$. Of course, such a tendency as $X_{\mathrm{C} 12 \mathrm{H} 26}$ decreases with decreasing $S / C$ is consistent with the increasing differences between experimental and theoretical molar fractions with decreasing $S / C$ as shown in Fig. 8. On the other hand, this tendency in $X_{\mathrm{C} 12 \mathrm{H} 26}$ is contrast to that in $C B E$. Concerning this contrast, we should remind that $X_{\mathrm{C} 12 \mathrm{H} 26}$ is determined using a total molar flow rate from the reactor (see Subsection 2.6). To obtain the total molar flow rate, we use a dryer filled with silica gel for steam removal, whose performance becomes worse at high temperature. Moreover, we need enough amount of silica gel, depending upon flow rate. In the present study, both total flow rate and dryer's temperature tend to increase with increasing $S / C$. So, for more precise discussion, we should diminish the experimental errors related with the steam removal from the outlet gas.

By the way, $C B E$ and $X_{\mathrm{C} 12 \mathrm{H} 26}$ are not rigorously identical with $0 \%$ and $100 \%$, respectively. These facts suggest that the reformed gas could involve unresolved $n$-dodecane. So, further researches for the identification of the components and move-complete resolution will be expected.

If we design actual steam reformers for $n$-dodecane referring to all the results in this section, the present results on both $C_{\mathrm{H} 2}$ and $X_{\mathrm{C} 12 \mathrm{H} 26}$ suggests such a valid criterion as the operation for $S / C \geq 4$ is appropriate. On the other hand, larger $S / C$ is not desirable, because of bulker total energy loss. Thus, we conclude that the operating condition like $S / C \simeq 4$ is the most suitable for practical steam reforming. We might expect that future studies will achieve the improvement toward larger $C_{\mathrm{H} 2}$, as well as the improvement toward the reduction of $S / C$ to such a theoretical limit as 2 . - For these improvements, uniform mixing 
is considered to be a key technology. For reference, the reforming efficiency $\eta$ of the present system is a little more than $50 \%$ at $S / C=4$, where $\eta$ is defined as the ratio of the calorific value of $\mathrm{H}_{2}$ involved in the outlet gas to the sum of the calorific value of $\mathrm{C}_{12} \mathrm{H}_{26}$ involved in the inlet gas and that from all the electric heaters and the burner. -

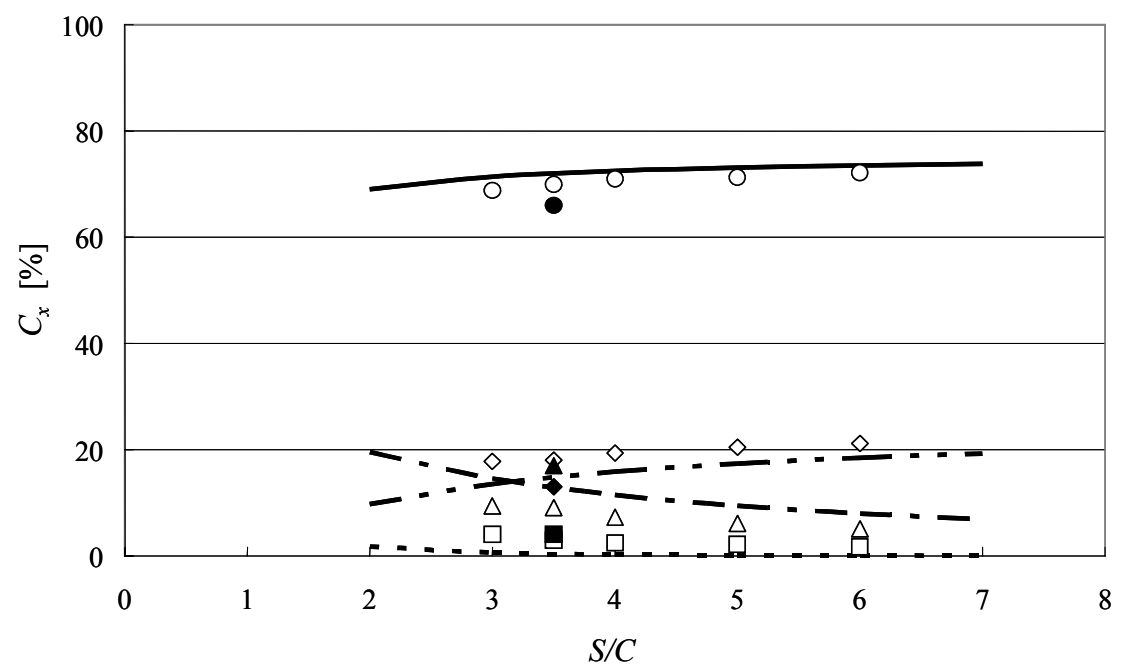

Fig. 8. Molar fraction $C_{x}$ by experiments versus steam-to-carbon molar ratio $S / C$ ( $L H S V=$ $\left.0.33 \mathrm{~h}^{-1}, Q_{\mathrm{d}}=4.0 \mathrm{cc} / \mathrm{min}, T_{\mathrm{VI}}=973 \mathrm{~K}, t=3600 \mathrm{~s}\right) . \quad \bigcirc$ and $\boldsymbol{O}, \mathrm{H}_{2} ; \quad \square$ and $\boldsymbol{\square}, \mathrm{CH}_{4}$; $\triangle$ and $\boldsymbol{\Delta}, \mathrm{CO} ; \diamond$ and $\diamond \mathrm{CO}_{2}$. $\bigcirc, \square, \triangle$ and $\diamond$, The present; $\boldsymbol{Q}, \boldsymbol{\square}, \boldsymbol{\Delta}$ and $\checkmark$, Suzuki et al., $2000(S / C=3.5, T=1100 \mathrm{~K})$. Lines denote the thermal-equilibrium theory.

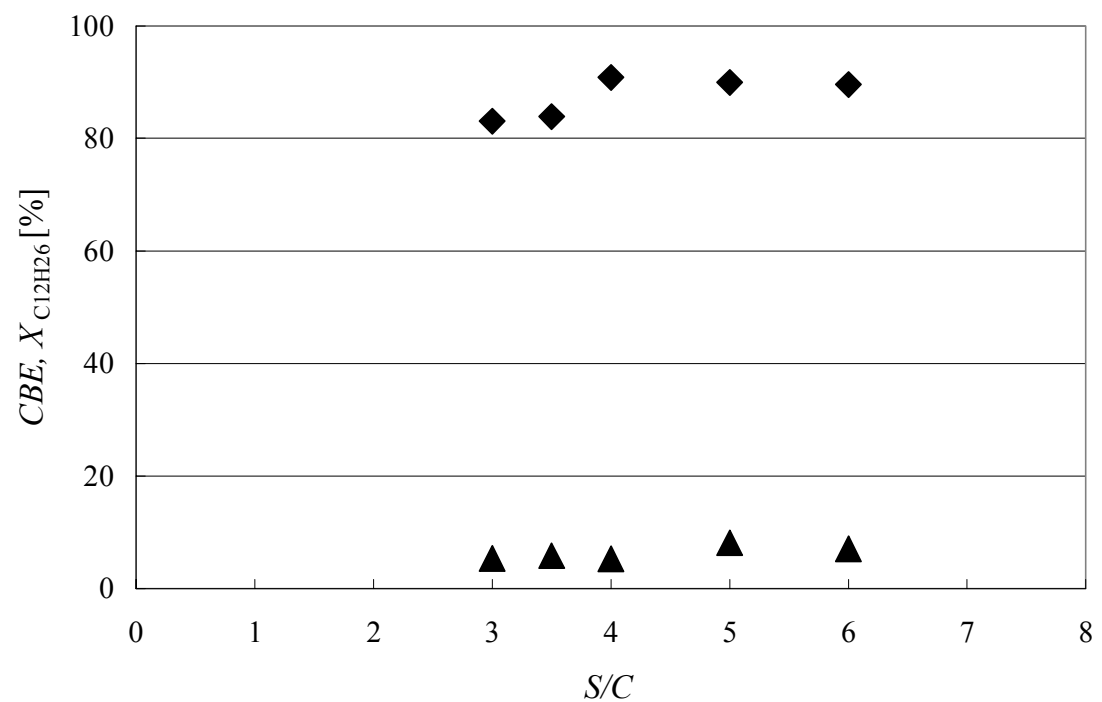

Fig. 9. Carbon-balance error $C B E$ and conversion ratio $X_{\mathrm{C} 12 \mathrm{H} 26}$ versus steam-to-carbon ratio $S / C\left(L H S V=0.33 \mathrm{~h}^{-1}, Q_{\mathrm{d}}=4.0 \mathrm{cc} / \mathrm{min}, T_{\mathrm{VI}}=970 \mathrm{~K}, t=3600 \mathrm{~s}\right) . \Delta, C B E$, $X_{\mathrm{C} 12 \mathrm{H} 26}$. 


\section{Conclusions}

Obtained results are as follows.

(1) We have examined $n$-dodecane as a heavy-hydrocarbons fuel without sulfur, which is a main constituent of kerosene. And, we have developed a small and simple steam-reformer in a home-use size. We have successfully achieved suitable inside-temperature profiles to satisfy practical temperature requirements, by the control of a thermal diffuser. Then, we have measured the molar fractions $C_{\mathrm{H} 2}, C_{\mathrm{CH} 4}, C_{\mathrm{CO}}$ and $C_{\mathrm{CO} 2}$ of main gas components, comparing to the numerical calculation based on the thermal-equilibrium theory.

(2) The inside-temperture profiles suggest that the steam-reforming reaction becomes more active at the position where temperature $T>800 \mathrm{~K}$. — Of course, we require the discussion on local heat consumption from a strict viewpoint. -

(3) We have shown the effects of steam-to-carbon ratio $S / C$ upon $C_{\mathrm{H} 2}, C_{\mathrm{CH} 4}, C_{\mathrm{CO} 2}$ and $C_{\mathrm{CO}}$, experimentally and theoretically. The experimental results agree with the theoretical ones. Besides, we have revealed the effects of $S / C$ upon both carbon-balance error and conversion ratio.

We could conclude that the operating condition like $S / C \simeq 4$ is the most suitable for practical steam reforming. We might expect that future studies will achieve the improvement toward larger $C_{\mathrm{H} 2}$, as well as the improvement toward the reduction of $S / C$ to such a theoretical limit as 2 . For these improvements, uniform mixing is considered to be a key technology.

\section{Acknowlegements}

This work is the revision and extension of the paper in RE2010 International Conference in Yokohama with the paper number O-Hf-6-4. The opportunity is gratefully acknowledged. We also appreciate technical supports by Mr Masaaki Kamizono, Mr Koshi Katagiri, Mr Daisuke Yamada and Mr Yasunari Murawaka (Doshisha University)

\section{References}

(1) K. Hirata, Y. Sono, Y. Okuhigashi, T. Shinoki and J. Funaki, "Hydrogen production from ethanol by steam reforming with $\mathrm{Cu} / \mathrm{ZnO} / \mathrm{Al}_{2} \mathrm{O}_{3}$," Trans. JSME (Series B), 76(763), pp. 412-414, 2010 (in Japanese).

(2) T. Shinoki, K. Ota, Y. Sono, Y. Okuhigashi, J. Funaki and K. Hirata, "Hydrogen production using an ethanol-steam-reforming reactor with $\mathrm{Cu} / \mathrm{ZnO} / \mathrm{Al}_{2} \mathrm{O}_{3}$ catalyst," Journal of Power and Energy Systems, 5(3), pp. 218-228, 2011.

(3) T. Suzuki, H. Iwami and T. Yoshinari, "Steam reforming of kerosene on $\mathrm{Ru} / \mathrm{Al}_{2} \mathrm{O}_{3}$ catalyst to yield hydrogen," International Journal of Hydrogen Energy, 25, pp. 119-126, 2000.

(4) T. Fukunaga, H. Katsuno, H. Matsumoto, O. Takahashi and Y. Akai, "Development of kerosene fuel processing system for PEFC," Catalysis Today, 84, pp. 197-200, 2003.

(5) Y. Kobori, T. Matsumoto, I. Anzai, S. Ueno and Y. Oishi, "Kerosene reforming catalyst for fuel cell application -kinetic and modeling analysis of steam reforming-," Science and Technology in Catalysis 2002, Kodansha Ltd., pp. 477-478, 2003.

(6) K. Saito and T. Kisen, "Development of kerosene reforming technology for fuel cell," Idemitsu Giho, 46(1), pp. 51-57, 2003 (in Japanese).

(7) D. J. Liu, D. Kaun, H. K. Liao and S. Ahmed, "Characterization of kilowatt-scale autothermal reformer for production of hydrogen from heavy hydrocarbons," 
International Journal of Hydrogen Energy, 29, pp. 1035-1046, 2004.

(8) H. Koseki, "Flame stability limit and exhaust emissions of low calorific fuel combustion in turbulent diffusion combustor for a small-scale fuel cell," JSME International Journal, 47(2), pp. 221-227, 2004.

(9) T. Muramoto, K. Nariai, H. Ohara and H. Kamata, "Durability of $\mathrm{Ru} / \mathrm{CeO}_{2} / \gamma-\mathrm{Al}_{2} \mathrm{O}_{3}$ catalyst for steam reforming of dodecane," Journal of the Japan Petroleum Institute, 52(3), 108-113, 2009.

(10) S. Yoon, J. Bae, S. Kim and Y. S. Yoo, "Self-sustained operation of a $\mathrm{kW}_{\mathrm{e}}$-class kerosene-reforming processor for solid oxide fuel cells," Journal of Power Sources, 192, pp. 360-366, 2009.

(11) T. Shinoki, F. Kataoka, Y. Fujimoto, H. Tanigawa, J. Funaki and K. Hirata, "Hydrogen production by a reactor for heavy hydrocarbons," Trans. JSME (Series B), 77(776), pp. 939-943, 2011 (in Japanese).

(12)H. Matsumoto, "High-concentration-hydrogen production technology for kerosene," Suisoriyougijutusyusei, NTS, Tokyo, pp. 120-137, 2003 (in Japanese).

(13) H. Uematsu, Fuel-Cell Generation System and Thermal Balance, Ohm-sha, Tokyo, pp. 71-83, 2004 (in Japanese).

(14)H. Uematsu, Fuel-Cell Generation System and Thermal Balance, Ohm-sha, Tokyo, p. 79, 2004 (in Japanese).

(15) A. Valant, A. Garron, N. Bion, F. Epron and D. Duprez, Catalysis Today, 138, pp.169-174, 2008. 